\title{
Monoclonal Antibodies Against Surface Antigens of Vibrio Anguillarum Serogroup 02
}

\author{
By Ivan Svendsen and Jens Laurits Larsen
}

\begin{abstract}
Svendsen, I. and J. L. Larsen: Monoclonal antibodies against surface antigens of Vibrio anguillarum serogroup 02. Acta vet. scand. 1988, 29, 363-368. - Monoclonal antibodies to Vibrio anguillarum 0-group 2 (MAB 02) were used to compare the cell surface determinants of $V$. anguillarum 0 -groups 1 and 2 , and $V$. ordalii. In the homologous system a significant reactivity was found, while MAB 02 clones showed a very low-graded cross-reactivity to $V$. anguillarum 01 and $V$. ordalii. The importance of these aspects in the selection of adequate vaccine strains is discussed, with an emphasis on the improvement of vibriosis vaccines.
\end{abstract}

vibrio ordalii; vaccination.

\section{Introduction}

Vibriosis in marine fish, feral as well as cultured, is caused by a wide range of Vibrio anguillarum 0-groups (Sørensen \& Larsen 1986, Tajima et al. 1985). Among these 0groups, 01 and 02 comprise the most important strains involved in infections in cultured fish, with a proportional prevalence of $85-90 \%$. the predominant group in salmonids is 01 , while 02 dominates among other species (Sørensen \& Larsen 1986, Tajima et al. 1985).

Pathogenic 0 strains possess a plasmid ( $\mathrm{CrO}$ sa 1980), a $\mathrm{K}$ antigen (Rasmussen 1987a), and extracellular products (Inamura et al. 1984, Kodama et al. 1985) that may be important pathogenicity and virulence factors. For the 02 group the situation is rather complex. Firstly, Vibrio anguillarum biotype 2, serotype II, was separated from Vibrio anguillarum as a new species, Vibrio ordalii (Schiewe et al. 1981). Secondly, polyacryla- mid gel electrophoresis and chemical analysis of phenol-water extracts have demonstrated major differences in the composition of LPS from Vibrio anguillarum and Vibrio ordalii (Chart \& Trust 1984, Salati \& Kusudu 1986). Thirdly, Vibrio ordalii possesses a plasmid (Schiewe \& Crosa 1981), while the importance of plasmids in Vibrio anguillarum 02 is not yet conclusively demonstrated. Despite a rather pronounced taxonomic difference between Vibrio anguillarum and $\mathrm{Vi}$ brio ordalii (Schiewe et al. 1981), there is a serological cross-reactivity between Vibrio anguillarum 02 and Vibrio ordalii when using polyclonal antibodies (Chart \& Trust 1984, Sørensen \& Larsen 1986), and, in fact, many commercial vaccines are based on $\mathrm{Vi}$ brio anguillarum 01 with Vibrio ordalii as the representative for the 02 group.

Monoclonal antibodies provide several advantages over conventional polyclonal antisera derived from immunization of animals 
with antigenic fractions. For example, they have defined specificity for a single epitope on a macro-molecule. This permits an accurate quantification and identification of interesting macro-molecules under most circumstances, regardless of the presence of contaminating antigens.

Monoclonal antibodies against the 0 -antigenic determinants will also be valuable in the quality control of future vaccines. One of the major problems in vaccine control is the stability of the bacterial strain used for production. Monoclonal antibodies will provide the most specific reagents available for the detection of any changes in the surface antigens or the strains.

The aim of this study is to use monoclonal antibodies against Vibrio anguillarum 02 for screening Vibrio anguillarum and Vibrio ordalii strains, and to test commercial vaccines for their content of serogroup 02 antigenic determinants.

\section{Materials and methods \\ Strains}

Donor strain used for the production of monoclonal antibodies was SFA45, a clinical isolate from Salmo salar, received from Dr. T. Håstein, Oslo. This strain and the test strains are listed in Table 1 showing the 0group, origin, and source of the strains. The strains examined were Vibrio anguillarum serogroups 01 and 02 and Vibrio ordalii. Bacteria for immunization and cross-reaction studies were grown in shaker cultures in tryptic soy broth (TSB Difco) with $1.5 \%$ $\mathrm{NaCl}$ for $24 \mathrm{~h}$, and then killed with formalin.

\section{Immunization program}

Female BALB/c mice were injected with 0.1 mg wet weight of Vibrio anguillarum 02 bacteria (SFA 45) per mouse. In the first injection the antigen preparation was emulsified with Freund's complete adjuvant and injected subcutaneously. A booster injection without adjuvant was given after a resting period of 1 month.

\section{Production of monoclonal antibodies}

Four days after the booster injection, spleen cells were fused with a mouse myeloma line $\mathrm{X} 63 \mathrm{Ag} 86.5 .3$ as described by Larsen et al. (1984). Hybridomas were sub-cloned by the limiting dilution method and screened for antibody activity in an ELISA assay using formalinized bacteria as antigen.

\section{Enzyme-Linked Immunosorbent Assay}

An ELISA was performed using polystyrene 96-well microtiter plates (Nunc immunoplates I). Whole bacterial cells were coated onto the plate using glutaraldehyde. A $100 \mu \mathrm{l}$ volume of $0.25 \%$ wet weight/volume bacterial cells in PBS, pH 7.4, were applied to each well, followed by the addition of $100 \mu \mathrm{l}$ of $0.25 \%$ glutaraldehyde in PBS. The plates were centrifuged for $10 \mathrm{~min}$ at $1,500 \mathrm{~g}$. After two rinses with a washing-buffer (sodium phosphate $8 \mathrm{mmol} / 1, \mathrm{NaC} 10.5 \mathrm{~mol} / 1, \mathrm{KC} 1$ $0.2 \mathrm{mmol} / \mathrm{l}$, and $1 \%$ Triton $\mathrm{x}-100, \mathrm{pH} 7.2$ ) the uncoated binding sites were blocked by adding $200 \mu \mathrm{l}$ of blocking-buffer (washingbuffer + bovine albumin $1 \%, \mathrm{pH} 7.2$ ). The cells were blocked overnight at $4^{\circ} \mathrm{C}$.

Bound monoclonal antibodies were detected by the application of $100 \mu$ l of hybridoma supernatant to each well, followed by incubation for $1 \mathrm{~h}$. The wells were washed 3 times with washing-buffer; $50 \mu \mathrm{l}$ of peroxidase-labelled goat anti-mouse immunoglobulin (TAGO, USA), diluted 1:1,000 in blockingbuffer, was added to each well, and the plates were incubated for $1 \mathrm{~h}$. After 4 washes, $100 \mu \mathrm{l}$ of 1.2 -phenylenediamine dihydrochloride $(2.2 \mathrm{mmol} / \mathrm{l})$ in a sodium citrate buffer $0.1 \mathrm{mmol} / \mathrm{l}$, pH 5.0, with hydrogen peroxide $6.5 \mathrm{mmol} / \mathrm{l}$, was added to each well. Af- 
Table 1. Vibrio anguillarum and Vibrio ordalii strains.

\begin{tabular}{lrll}
\hline Strain & O-group & Origin & Source \\
\hline V. anguillarum & & & \\
$9006 / 1$ & 1 & Rainbow trout, Denmark & J. L. Larsen \\
SFA 36 & 1 & Rainbow trout, Norway & T. Hảstein \\
SFA 46B & 1 & Rainbow trout, Norway & E. Egidius \\
SFA 39 & 2 & Cod, Norway & T. Hảstein \\
SFA 45 & 2 & Salmon (salar), Norway & T. Håstein \\
SFA 50 & 2 & Rainbow trout, Sweden & O. Ljungberg \\
6087 G & 2 & Rainbow trout, Denmark & J. L. Larsen \\
& & & \\
V. ordalii & & & \\
MSC-2-75 & 2 & Salmon (coho), USA & J. L. Fryer \\
DF K $_{24-S}^{241-S}$ & 2 & Salmon (coho), USA & M. H. Schiewe \\
& 2 & Salmon (sockeye), USA & M. H. Schiewe \\
\hline
\end{tabular}

ter incubation, the colour development was stopped by adding $100 \mu \mathrm{l}$ sulphuric acid $2 \mathrm{~N}$. Optical density was measured at $492 \mathrm{~nm}$ in an SLT 210 Multiscan Photometer (SLT, Austria).

\section{Vaccines}

Three commercial vaccines were obtained and tested with the MAB-02: Fiskevax, Coopers Animal Health, Ltd., England; Biovax, Biomedical Research Laboratories, Inc., USA; Vibriovax, Leo Vet., Denmark.

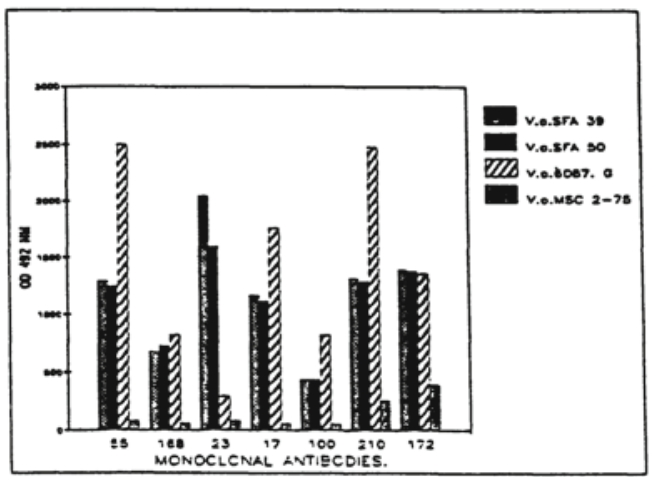

Figure 1. Reactions of monoclonal antibodies 02 with 3 Vibrio anguillarum 02 and 1 Vibrio ordalii. Donor strain V.a SFA 45, cf. Fig 4.

\section{Results}

Fifteen clones were tested, and 7 of these were selected on the basis of their specificity and reactivity with SFA45 and other Vibrio anguillarum strains.

Fig. 1 illustrates the reactions between the 7 different clones of monoclonal antibodies to Vibrio anguillarum 02 (MAB-02) and 3 different Vibrio anguillarum 02 strains and $V i$ brio ordalii MSC-2-75. All clones give a strong reaction with the Vibrio anguillarum strains, while only 2 clones give a very weak reaction to Vibrio ordalii.

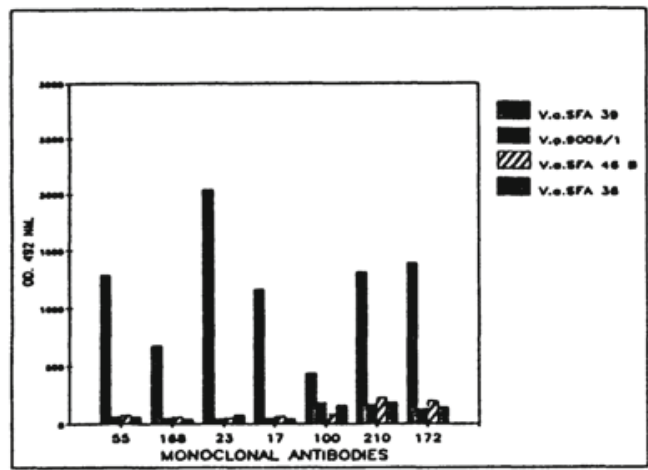

Figure 2. Reactions of monoclonal antibodies 02 with 1 Vibrio anguillarum 02 and 3 Vibrio anguillarum 01. Donor strain V.a. SFA 45. 
In Fig. 2 is shown how the different MAB-02 clones react with Vibrio anguillarum 01 and a homologous strain. The reactions in the heterologous system are very weak, and as previously there is a strong reaction with the 02 strain.

When testing 3 Vibrio ordalii strains (Fig. 3) it was found that all strains gave identical low-grade reactions with MAB 55, 168, 23, 17 , and 100 , while a little stronger reaction was found with MAB 210 and 172. An 02 strain was used as the control.

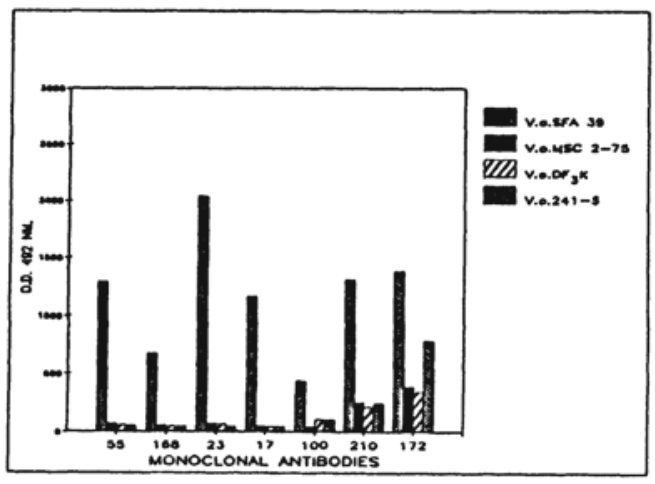

Figure 3. Reactions of monoclonal antibodies 02 with 1 Vibrio anguillarum 02 and 3 Vibrio ordalii. Donor strain V.a. SFA 45.

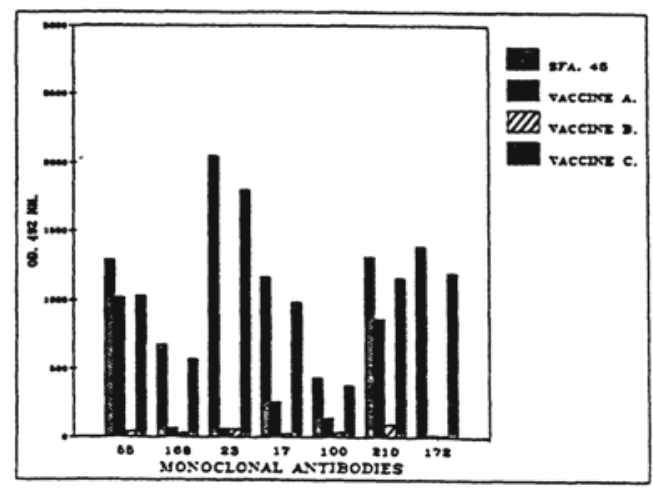

Figure 4. Reactions of monoclonal antibodies 02 with Vibrio anguillarum 02 (i.e. the donor strain) and 3 commercial vaccines: $\mathrm{A}, \mathrm{B}$, and $\mathrm{C}$.
The MAB-02 clones were used in a test of 3 commercial vaccines (Fig. 4). Vaccine A, containing a Vibrio anguillarum 02 strain, gave a strong reaction with clones 55 and 210 , while vaccine $B$, with Vibrio ordalii as 02 component, was practically non-reactive with any of the 7 clones. Vaccine C, composed of Scandinavian isolates of Vibrio anguillarum 01 and 02 , gave an excellent reaction with all the clones produced by using strain SFA 45.

\section{Discussion}

Monoclonal antibodies (MAB) have proved to be highly specific for defining antigenic epitopes on the bacterial surface. In this paper we have focussed on Vibrio anguillarum serogroup 02 , which seems to be the most controversial component in commercial vibriosis vaccines.

As Vibrio ordalii has been regarded as the Vibrio anguillarum serotype II (Schiewe et al. 1981, Johnson 1980), this species has been selected for use in many vaccines. $\mathrm{Vi}$ brio ordalii has, however, not been isolated in Europe (Austin \& Austin 1987). Vibrio anguillarum, which is predominant here, contains many strains of 02 which crossreact with Vibrio ordalii (Sørensen \& Larsen 1986). Emphasis should, however, be placed on the 0-group, as protection was suggested to be made through antibodies to the "O« antigen (Harrell et al. 1975).

By use of different MABs we tried to get an impression of the cross-reactivity between Vibrio anguillarum and Vibrio ordalii strains (Figs. 1-3). It was evident that the clones of MAB did not show much reactivity to the surface antigens of Vibrio anguillarum 01 and Vibrio ordalii. Concerning Vibrio ordalii it was found that 5 clone gave practically no reaction with the bacterium, while 2 clones gave partial cross-reaction, a fact which could explain the cross-reactivity 
measured by the use of polyclonal or conventional antisera (Chart \& Trust 1984, Sørensen \& Larsen 1986). In the homologous system it was found that Vibrio anguillarum 02 strains gave a very extensive cross-reaction with all the clones.

Serogroup 02 is responsible for approximately $15 \%$ of the cases of vibriosis among salmonids and $80 \%$ in other species (Sørensen \& Larsen 1986, Tajima et al. 1985). Since many antigenic determinants of Vibrio anguillarum 02 probably do not occur in $\mathrm{Vi}$ brio ordalii, it might be expected that protection is not obtained in all cases of vibriosis with Vibrio anguillarum 02 as the causative agent. It seems imperative to emphasize some fundamental principles when a vaccine is constructed, such as which fish species should be protected, what geographical zone should be covered, and what is the serological distribution or variety in the local strains of Vibrio anguillarum, or does Vibrio ordalii occur?

Recently, Rasmussen (1987a) described a K antigen in Vibrio anguillarum 01, and further studies showed that 02 contained two antigenic sub-groups, 02a and 02b (Rasmussen 1987b). Therefore it should be concluded that production of vibriosis vaccines might be more complicated than previously suggested (Johnson 1980). The candidate strains must be selected on the basis of epidemiological studies with a detailed analysis of the antigenic determinants on the responsible Vibrio strains. Nevertheless, vibriosis vaccines have, been rather successful hitherto (Gudding et al. 1985, Horne 1984).

On the other hand considering the way present vaccines are produced (Fig. 4), there must be great room for improvement; actually, it seems very difficult to rely on vaccines with such a low level of cross-reactivity to surface antigens of the local representative for 02 from which the MAB was produ- ced. Thus, Vibrio ordalii should not be considered relevant in vaccines used in areas where Vibrio anguillarum strains are responsible for vibriosis. Among Vibrio anguillarum strains it is important to use representatives covering an antigenic spectrum as broad as possible, and probably a strain of each of the antigenic sub-groups $02 \mathrm{a}$ and $02 \mathrm{~b}$ should be recommended (Rasmussen 1987b).

Monoclonal antibodies have shown interesting qualities in studies of Vibrio anguillarum strains and vibriosis vaccines. It is, however, important to know the real nature of the determinats to which the MAB are directed. A test with LPS extract produced by the hot phenol water procedure as described by Westphal et al. (1952) showed that MAB clone 17 reacted specifically with this component. Further research should clarify the nature of other antigenic determinants.

\section{Acknowledgement}

The financial support of Nordisk Ministerråd is greatly appreciated.

\section{References}

Austin B, Austin DA: Bacterial fish pathogens, disease in farmed and wild fish. Ellis Horwood Ltd., Chichester, England 1987, pp. 283-285.

Chart H, Trust TJ: Characterization of the surface antigens of the marine fish pathogens Vibrio anguillarum and Vibrio ordalii. Can. J. Microbiol. 1984, 30, 703-710.

Crosa JH: A plasmid associated with virulence in the marine fish pathogen Vibrio anguillarum specifies an iron-sequestering system. Nature 1980, 284, 566-568.

Gudding $R$, Hästein $T$, Naess B: Vaksinasjon av oppdrettsfisk. (Vaccination of cultured fish). Norsk Veterinærtidsskrift 1985, 97, 167-172.

Harell LW, Etlinger HM, Hodgins HO: Humoral factors important in resistance of salmonid fish to bacterial disease. I. Serum antibody protection of rainbow trout (Salmo gairdneri) against vibriosis. Aquaculture 1975, 6, 211-219. 
Inamura $H$, Muroga $K$, Nakai $T$ : Toxicity of extracellular products of Vibrio angiullarum. Fish $\mathrm{Pa}$ thol. 1984, 19, 89-96.

Johnson KA: Development of effective Vibrio vaccination program for salmonid culture. Fish $\mathrm{Pa}$ thol. 1980, 14, 4.

Kodama H, Moustafa M, Mikami T, Izawa H: Partial purification of extracellular substance of $\mathrm{Vi}$ brio anguillarum toxigenic for rainbow trout and mouse. Fish Pathol. 1985, 20, 173-179.

Larsen F, Selmer J, Hertz J: Purification of Bordetella pertussis antigens using monoclonal antibodies. Acta Path. Microbiol. Immunol. Scand. Sect. C 1984, 92, 271-277.

Rasmussen $H B$ : Evidence for the presence of a $\mathrm{K}$ antigen in strains of Vibrio anguillarum. Curr. Microbiol. 1987a, 14, 275-278.

Rasmussen $H B$ : Subgrouping of lipopolysaccharide 0 antigens from Vibrio anguillarum serogroup 02 by immunoelectrophoretic analyses. Curr. Microbiol. 1987b, 16, 39-42.

Salati F, Kusuda R: Chemical composition of the lipopolysaccharides from Vibrio anguillarum and Vibrio ordalii. Fish Pathol. 1986, 21, 193-199.

Schiewe MH, Crosa JH: Molecular characteristics of Vibrio anguillarum biotype 02 . Can. J. Microbiol. 1981, 27, 1011-1018.
Schiewe MH, Trust TJ, Crosa JH: Vibrio ordalii sp. nov.: A causative agent of vibriosis in fish. Curr. Microbiol. 1981, 6, 343-348.

Sørensen UBS, Larsen JL: Serotyping of Vibrio an. guillarum. Appl. Environ. Microbiol. 1986, 51, 593-597.

Tajima K, Ezura Y, Kimura T: Studies on the taxonomy and serology of causative organisms of fish vibriosis. Fish Pathol. 1985, 20, 131-142.

Westphal $O$, Lüderetz $O$, Beter $F$ : Über die Extraktion von Bakterien mit Phenol/Wasser. (On the extraction of bacteria with phenol/water). Z. Naturforsch. 1952, $7 B, 148-155$.

\begin{abstract}
Sammendrag
Monoklonale antistoffer mod overflade-antigener hos Vibrio anguillarum.

Monoklonale antistoffer mod Vibrio anguillarum $\mathrm{O}$ gruppe 2 (MAB 02) blev fremstillet for at kunne sammenligne overflade-antigene determinanter pá $V$. anguillarum 01 og 02 samt $V$. ordalii. I det homologe system fandtes en kraftig reaktion mellem MAB 02 og 02-stammerne, derimod var der meget lidt krydsreaktion med $V$. anguillarum 01 og $V$. ordalii. Dette forhold har stor betydning, nảr der skal udvælges stammer til vaccineproduktion, og med denne baggrund diskuteres mulighederne for forbedring af vibriose-vaccinerne.
\end{abstract}

(Received October 6, 1987; accepted February 5, 1988).

Reprints may be requested from: J. L. Larsen, Institute of Hygiene and Microbiology, Royal Veterinary and Agricultural University, 13 Bülowsvej, DK-1870 Frederiksberg C, Denmark. 